\title{
TRATAMENTO ORTODÔNTICO EM PACIENTES ADULTOS COM PERIODONTO REDUZIDO
}

\section{ORTHODONTIC TREATMENT IN ADULTS PATIENTS WITH REDUCED PERIODONTICS}

\author{
Renata Moya Martelli ${ }^{1}$ Nádia Cristina Fecchio Nasser Horiuchi ${ }^{1}$ Vanessa Carla de Queiroz Neves ${ }^{1}$ \\ Adiron Alcides Mehret ${ }^{2}$ Juliana Rico Pires ${ }^{3}$ Benedicto Egbert Corrêa de Toledo ${ }^{3}$ \\ 1- Cirurgiã-Dentista. Mestre em Ciências Odontológicas pelo Programa de Pós-Graduação em Ciências \\ Odontológicas do Centro Universitário da Fundação Educacional de Barretos - UNFEB. Av. Professor \\ Roberto Frade Monte n ${ }^{\circ}$ 389, Aeroporto, CEP 14783-226, Barretos, SP, Brasil, Telefone (17) 3321.6468, \\ Fax (17) 3322.05622 \\ 2- Professor do Curso de Especialização em Ortodontia, FUNORTE/SOEBRAS, Campus Lins. Mestre \\ em Ciências Odontológicas pelo Programa de Pós-Graduação em Ciências Odontológicas do Centro \\ Universitário da Fundação Educacional de Barretos - UNFEB. Rua Tupi nº 15, Xingu, CEP: 16400-377, \\ Lins, SP, Brasil. Telefone (17)3532-1761 \\ 3- Mestre e Doutores em Periodontia. Professores do Programa de Pós-Graduação em Ciências Odontológicas \\ e do Curso de Graduação em Odontologia, Centro Universitário da Fundação Educacional de Barretos, \\ Av. Professor Roberto Frade Monte n ${ }^{\circ} 389$, Aeroporto, CEP 14783-226, Barretos, SP, Brasil, Telefone (17) \\ 3321.6468, Fax (17) 3322.05622
}

\section{RESUMO}

Durante muito tempo, o tratamento ortodôntico ficou restrito quase que exclusivamente a pacientes jovens, sendo o tratamento em adultos incomum e considerado por alguns como inviável. Atualmente, devido à maior longevidade da população, tem aumentado muito o número de pacientes adultos que procuram por tratamento ortodôntico. Independente do motivo, a ortodontia nesses pacientes requer uma abordagem própria, pois se observa uma demanda de pacientes adultos com problemas periodontais em busca de tratamento ortodôntico por motivos estéticos, ou por solicitação de outras especialidades. O presente estudo teve como objetivo mostrar, mediante revisão de literatura, que é possível tratar de maneira eficiente esses casos, e que o sucesso desta intervenção depende da realização de um planejamento multidisciplinar e da consideração especial para alguns aspectos importantes, como: a presença de inflamação, a qualidade do suporte ósseo, o tipo de movimento, a força a ser aplicada e a colaboração do paciente.

Palavras-chave: Ortodontia em adultos. Periodonto reduzido. Tratamento interdisciplinar.

\begin{abstract}
For a long time orthodontic treatment was restricted almost exclusively to young patients, and the treatment of adults was unusual and is considered by some to be infeasible. Currently, due to the increased longevity of the population, these treatments have greatly increased the number of adult patients seeking orthodontic treatment. Whatever the reason, orthodontics for adult patients requires a tailored approach, because there is a demand for adult patients with periodontal problems seeking orthodontic treatment for aesthetic reasons, or solicitation of other specialties. The present study aimed to show, through a literature review, that it is possible to handle these cases efficiently, and that the success of this intervention depends on
\end{abstract}

Autor para correspondência: Renata Moya Martelli e-mail: re.moya@hotmail.com Telefone: Telefone (14) 3523-5175

Recebido em: 06/05/2013

Aceito para publicação em: 22/03/2015

https://doi.org/10.4322/1980-0029.202014 
the realization of a multidisciplinary planning and special consideration for some important aspects such as the presence of inflammation the quality of the bone support, the type of movement, the force to be applied, and patient compliance

Keywords: Orthodontics in adults. Periodontal reduced. Interdisciplinary treatment.

\section{INTRODUÇÃO}

A perda de suporte periodontal pode ocasionar a migração patológica dos dentes, resultando em alongamento, afastamento e inclinação vestibular de incisivos, rotação e inclinação de pré-molares e molares, ocasionando problemas de oclusão (Zachrisson \& Bjorn, 2005). O tratamento ortodôntico, nesses casos, visa movimentá-los para posições que possibilitem estabilizá-los, tirá-los de interferências e contatos oclusais prematuros, diminuindo defeitos ósseos, facilitando a higienização, melhorando a estética e o prognóstico da dentição.

Devido a esses fatores, há um maior interesse de indivíduos adultos pelos benefícios da ortodontia (Carraro \& Jimenez-Pellegrin, 2009; Pithon $\&$ Bernardes, 2005), e também o fato de que é crescente a busca da população, em geral, pela preservação de sua dentição natural. Contudo, o tratamento ortodôntico realizado de forma inadequada em pacientes periodontais pode certamente contribuir para futuro colapso dos tecidos de suporte periodontal (Finkbeiner et al., 1997; Bassani et al., 2001; Cirelli \& Cirelli, 2003). A combinação de inflamação, força ortodôntica e trauma oclusal pode produzir uma destruição mais acelerada dos tecidos de suporte periodontal, do que quando se tem a inflamação isoladamente (Zachrisson, 2005). É clinicamente essencial que o tratamento periodontal, com a eliminação da placa bacteriana, seja realizado antes do tratamento ortodôntico. Os pacientes devem ser orientados quanto à higiene oral durante todo o tratamento ortodôntico (Zachrisson, 1996).

Observações clínicas e radiográficas (Costa et al., 2002; Nishi et al., 2011) confirmam e levam a acreditar que todo o paciente, seja ele saudável ou portador de doença periodontal, possa ter um tratamento ortodôntico, desde que os princípios básicos sejam executados e mantidos. Desta maneira, a cooperação interdisciplinar, periodontia e ortodontia, pode transformar pacientes que apresentam problemas dentários e gengivais esteticamente não atraentes em pessoas com um sorriso bonito e com saúde bucal, tornando-as clinicamente mais sociáveis (Mathews \& Kokich,
2001; Cirelli \& Cirelli, 2003; D’Ornellas et al., 2003; Zachrisson \& Bjorn, 2005).

\section{PROPOSIÇÃO}

Assim, o objetivo deste estudo foi realizar uma revisão de literatura e discorrer sobre a indicação do tratamento ortodôntico em pacientes com o periodonto reduzido.

\section{REVISÃO DE LITERATURA}

Ericsson et al. (1977) realizaram um estudo em cães e demonstraram que, na presença de biofilme bacteriano e inflamação gengival, a movimentação ortodôntica aumenta a taxa de destruição do periodonto de inserção e os movimentos ortodônticos de inclinação e/ou intrusão de dentes, que possuem biofilme bacteriano aderido, podem causar a formação de bolsas periodontais.

Zachrisson (1996), analisando as implicações clínicas da inter-relação ortodontia e periodontia, conclui que o elemento-chave no tratamento ortodôntico de pacientes adultos com doença periodontal é a redução ou eliminação de acúmulo de placa e da inflamação gengival. Por essa razão, esse tratamento deve dar ênfase às instruções de higiene oral, ao planejamento e construção do aparelho ortodôntico e às revisões periódicas durante o tratamento.

Comparando a reação do tecido seguida da aplicação de forças extrusivas e intrusivas em dentes de macacos adultos, Melsen (1986) concluiu que é possível aumentar osso alveolar nos dentes de extrusão, e que este osso pode ser mantido durante a intrusão. Salienta que a intrusão pode ser considerada um tópico muito controverso na literatura ortodôntica, mas que é visto como um caminho lógico para melhorar sobremordida profunda em pacientes adultos que têm dentes alongados. Conclui que a intrusão pode constituir um método terapêutico realizável no tratamento ortodôntico de adulto com uma condição de saúde periodontal avançada, e que não resulta em diminuição do nível do osso marginal em macacos periodontalmente saudáveis, providos 
de inflamação gengival controlada. Acrescenta que na realização do tratamento ortodôntico, o controle da placa bacteriana, fator primário para prevenção da doença periodontal, é relevante para se obter sucesso terapêutico.

Finkbeiner et al. (1997) estudaram os efeitos periodontais das bandas elásticas ortodônticas, demonstrando que tais bandas induziam periodontite e que a proservação demonstrou maturação da porção das raízes, mobilidade e recessão gengival. Concluíram que a interação entre ortodontia e periodontia é de extrema importância para uma correta evolução do tratamento.

Nelson \& Artun (1997), propondo estudar a evolução, prevalência e severidade da perda óssea alveolar em pacientes ortodônticos adultos, observaram 343 pacientes com idades entre 20 e 70,1 anos e verificaram que a perda óssea foi comum nos dentes anteriores, com média de 0,74mm por dente. Em 36\% dos casos, houve perda óssea em uma ou mais superfícies maior ou igual a $2 \mathrm{~mm}$. Não foi verificada relação entre o nível de perda óssea e a duração do tratamento, quantidade de movimentação horizontal e vertical.

Ong et al. (1998), comentando a inter-relação entre a periodontia e o tratamento ortodôntico de pacientes adultos, afirmam que a saúde periodontal é essencial para algumas formas de tratamento dental, e por isso os pacientes adultos precisam manter uma instrução de higiene bucal regular e manutenção periodontal em ordem, para assegurar tecido gengival saudável durante o tratamento ortodôntico ativo, e que existe a necessidade de um monitoramento de perto desses pacientes pelo ortodontista.

Re et al. (2000) avaliaram a efetividade da terapia cirúrgica e não cirúrgica na manutenção da saúde periodontal após o tratamento ortodôntico. $\mathrm{O}$ tratamento cirúrgico foi realizado em 267 pacientes afetados por doença periodontal severa, e em 128 pacientes somente o tratamento não cirúrgico foi realizado. Cada dente envolvido na movimentação ortodôntica foi controlado pela medida da profundidade de sondagem e presença do sangramento gengival à sondagem, no início e aos 2, 4, 6, 10 e 12 anos do término do tratamento ortodôntico, com uma diferença estatisticamente significante entre os valores pré e pós-tratamento. Os autores concluíram que o tratamento ortodôntico não é uma contraindicação na terapêutica de adultos com periodontite severa, e que nesses casos a ortodontia melhora as possibilidades de preservação adequada e restauração de uma dentição deteriorada.

Mathews \& Kokich (2001) analisaram os problemas periodontias em pacientes tratados ortodonticamente e aconselham os ortodontistas a avaliarem os aspectos periodontais em uma consulta inicial, tais como sondagem dos dentes nas proximais dos molares superiores, furcas, área de caninos e laterais inferiores com apinhamento, gengiva inserida, e radiografia interproximal para a crista óssea. Adicionalmente, os autores orientaram os ortodontistas a encaminhar para um periodontista quando a gengiva inserida apresentar espessura menor que $2 \mathrm{~mm}$, previamente ao início da terapia ortodôntica. Ressaltaram a necessidade de avaliar parafunção, como o bruxismo e o uso de placa noturna. Os autores discutiram os benefícios da integração entre ortodontia e periodontia no tratamento de pacientes comprometidos periodontalmente, para um diagnóstico correto antes da terapia ortodôntica.

Bassani et al. (2001) comentaram que o osso alveolar sofre alterações do tipo reabsorções e aposições. As reabsorções ocorrem no lado de pressão, onde o ligamento periodontal está sendo comprimido. As aposições inversamente acontecem no lado de tensão, onde o periodonto encontra-se distendido e, portanto, exercendo uma força de tração sobre o osso alveolar. Em decorrência dessas forças, os dentes podem ser induzidos a diversos movimentos ortodônticos, como inclinação, verticalização, translação, torque, rotação, extrusão e intrusão. Cada movimento gera força de tensão e tração em cada dente, mantendo, assim, a espessura do ligamento constante. Essa capacidade de adaptação do ligamento às diferentes forças que incidem sobre ele é a chave de todos os tratamentos ortodônticos. Os autores relataram que a movimentação de dentes com o periodonto saudável reduzido, entretanto, é uma alternativa possível e que não tem potencial para causar a perda de inserção adicional, porém a movimentação em dentes com inflamação acarreta um risco aumentado de perda de inserção periodontal. Portanto, é indispensável o tratamento periodontal prévio ao tratamento ortodôntico. Sobre a intrusão ortodôntica, os autores relatam que esses movimentos podem ter consequências mais graves para a saúde periodontal, podendo transformar placas supra em subgengival, ocorrendo 
defeitos infraósseos, bem como migração apical de inserção epitelial.

É preciso lembrar que uma nova inserção através da intrusão ortodôntica deve ser cuidadosamente avaliada. Segundo Bassani et al. (2001), a recessão gengival é atribuída a várias causas etiológicas, mas a escovação traumática, a anatomia funcional e as inserções de freios e bridas são alvos de controvérsias, e muitas vezes a posição dental tem sido também apontada como fator de recessão gengival. Além das recessões gengivais, decorrentes da terapia ortodôntica, os movimentos de corpo podem causar alterações na anatomia gengival. Desde 1965, conhece-se o fator etiológico da inflamação, que é o biofilme dental supragengival, e no caso dos procedimentos de ortodontia, existe um acúmulo maior de placa bacteriana. Por esse motivo, ocorre uma piora do estado inflamatório marginal. Mas a correlação entre inflamação marginal e tratamento ortodôntico não parece ser verdadeira, e somente observam-se maiores inflamações marginais na presença de placa ou de aparelhos ortodônticos que dificultam o controle de placa. No aspecto inflamatório, ainda, as bandas ortodônticas são indiscutivelmente um fator dificultador no controle da placa, podendo propiciar edema da margem gengival, aumento da profundidade de sondagem e o estabelecimento de uma microbiota subgengival diferenciada. Portanto, deve ficar claro que a simples presença do dispositivo ortodôntico não é capaz de gerar perdas de inserção conjuntiva em paciente saudáveis. A suscetibilidade do paciente, neste momento, é um ponto-chave na discussão do papel da ortodontia no desenvolvimento de processos destrutivos do periodonto. Deve ficar claro que é indiscutível a necessidade de tratamento periodontal previamente à terapia ortodôntica e que, independentemente do aparato que o paciente esteja usando, a etiologia da inflamação é a placa bacteriana.

Choze et al. (2002) fizeram um estudo revisional sobre a importância da intrusão ortodôntica como coadjuvante na reabilitação periodontal de dentes com suporte reduzido. A literatura pesquisada foi consensual ao afirmar a importância do tratamento ortodôntico por meio dos pequenos movimentos ou movimentação dentária, como uma conduta importante auxiliar para dentes com suporte reduzido pela evolução da doença periodontal. Tal literatura também enfatizou que esses movimentos só deverão ser realizados através de forças leves e controladas, e em um periodonto livre de inflamação e/ou infecção.

Costa et al. (2002) fizeram uma investigação para avaliar a perda óssea alveolar pré e pós-tratamento ortodôntico, e o método usado foi avaliar séries radiográficas iniciais e finais de 30 pacientes na faixa etária entre 15 e 30 anos, submetidos a tratamento ortodôntico com aparelhagem fixa (Edgewise), com duração mínima de 1 ano e máxima de 4 anos. A média de perda óssea alveolar encontrada após o tratamento ortodôntico foi de $1,05 \mathrm{~mm}$. Em um total de 300 cristas ósseas avaliadas, $46,3 \%$ apresentaram redução do nível ósseo alveolar e 43,70\% apresentaram-se sem alterações. Em virtude de algumas alterações (distorções radiográficas, erupção incompleta, extrações dentárias ou substituição por implantes), $10 \%$ dos registros não puderam ser avaliados. Ao somarem a média de reabsorção radicular e a perda óssea alveolar, observaram uma perda de sustentação periodontal considerável ao final do tratamento, em relação à situação periodontal inicial. Acreditam que o profissional deva informar seus pacientes quanto às possíveis alterações periodontais que poderão surgir em virtude do tratamento ortodôntico, e que exames radiográficos periódicos de monitoramento durante o tratamento ortodôntico devem ser requeridos para identificar alterações a princípio simples, mas que podem se tornar severas.

Cirelli \& Cirelli (2003) analisaram a indicação e os riscos do tratamento ortodôntico no tratamento periodontal e ressaltam que a ortodontia, no planejamento do tratamento periodontal, amplia a oportunidade de um melhor prognóstico para a manutenção da dentição permanente, com a correção de maloclusões, favorecendo o psicológico e a mecânica para um controle adequado de placa bacteriana. Analisam que a importância clínica da migração dentária patológica, promovida pela doença periodontal, está na sua alta prevalência e nas possíveis consequências, destacando a dificuldade de controle de placa e o surgimento de trauma oclusal secundário, que podem favorecer a progressão da migração e da mobilidade, até a perda do dente. Outras situações frequentes em pacientes com problemas periodontais são os molares inclinados mesialmente em direção a espaços desdentados, que geralmente apresentam bolsa infraóssea e defeito ósseo angulado na face mesial, mas a verticalização dentária, por 
meio de ortodontia, tem apresentado resultados bastante favoráveis nesses casos. Salientam os autores que a prática da ortodontia causa alguns riscos ao paciente, como gengivite e hiperplasia, irritação mecânica da banda, irritação química pelo cimento, impacção entre o arco e o tecido gengival, maior dificuldade de higienização e aumento da profundidade de sondagem. Assim, concluem que o paciente periodontal apenas deve iniciar a ortodontia após a fase de tratamento da doença, e se inserido em um programa de terapia de suporte, pois nessas condições os riscos de complicações periodontais são praticamente nulos, diante dos benefícios que o tratamento integrado periodontia-ortodontia traz ao paciente.

D'Ornellas et al. (2003) discorrerem sobre a conduta ortodôntica perante o paciente adulto acometido de doença periodontal. Como protocolo de tratamento, para eles o importante é o controle periodontal antes, durante e também após a colocação do aparelho, e o início da ortodontia deverá ser 6 meses após o término da periodontia. Sobre as indicações, relatam a facilidade do tratamento restaurador, melhoramento da saúde periodontal e o estabelecimento de uma proporção coroa-raiz favorável, numa orientação vertical, fazendo com que as forças oclusais sejam no longo eixo do dente. Já as contraindicações seriam a presença de placa, dentes com prognóstico questionável com perda de inserção atingindo o terço apical, envolvimento de furca avançado e formas avançadas de periodontite. As vantagens da ortodontia para esses pacientes seriam melhoras na função, higienização, redução de cargas não axiais, ganho de inserção, redução de defeito ósseo, restituição da oclusão incisal, melhor anatomia periodontal, aumento do selamento labial e melhora da estética. Como desvantagem, os autores concluíram que os dentes poderiam voltar à posição original, formação de abscessos periodontais, dificuldade de higienização, recessão gengival, reabsorção radicular e óssea, mudança da placa bacteriana de supra para subgengival e ainda a necrose pulpar. O período de reativação deve ser de 3 a 4 semanas, podendo ser mudado de acordo com o caso do paciente. Existem limites inerentes ao tratamento desses pacientes, como a escolha de uma adequada ancoragem e, assim, o tratamento nessas circunstâncias visa ao restabelecimento estético e funcional somente dos dentes migrados, não tendo a pretensão de ser uma terapia ortodôntica corretiva total.
Segundo Zachrisson (2005), antes do início da terapia ortodôntica, deve-se verificar a espessura bucolingual do osso e dos tecidos moles, especialmente na área que vai sofrer pressão, devido à ortodontia. Caso a espessura seja pequena, faz-se necessária cuidadosa orientação de higiene bucal, antes, durante e após o tratamento, com o objetivo de reduzir o risco de recessão. Por outro lado, indica que o tempo de espera entre o tratamento periodontal e a colocação do aparelho ortodôntico deve ser de 2 a 6 meses, dependendo da motivação do paciente quanto à higienização bucal e, também, para que ocorra a reparação óssea.

O objetivo de Gusmão et al. (2005) foi, de forma concisa, expressar suas experiências com base na literatura científica e nos seus achados clínicos. Salientam que as principais razões para o tratamento ortodôntico são as maloclusões e, dentre as relacionadas com possíveis danos aos tecidos periodontais, estão os dentes mal posicionados, como apinhamento, diastemas e giroversões, mordida aberta ou cruzada, traspasse horizontal e/ou vertical acentuados. As maloclusões levam ao aumento das forças mecânicas, podendo exceder a tolerância dos tecidos periodontias, ocasionando o trauma oclusal. Essas desarmonias, juntamente com a placa bacteriana, contribuem para a instalação da gengivite marginal crônica, hiperplasia gengival, recessão gengival e periodontite crônica. A gengivite marginal crônica é a forma mais comum de doença periodontal associada à ortodontia, quando há ausência de programas específicos de controle de placa bacteriana. Quando a inflamação persiste, encontra-se a hiperplasia gengival e, na maioria das vezes, ela permanece após a remissão da inflamação, sendo necessária a intervenção cirúrgica para refazer a forma anatômica e funcional da gengiva.

Pithon \& Bernardes (2005) afirmam que, atualmente, o tratamento ortodôntico em pacientes adultos vem se tornando uma rotina nos consultórios ortodônticos. Trata-se do paciente acima dos 18 anos no qual o crescimento já cessou. Associado à falta de crescimento, muitos deles têm outras particularidades, como doença periodontal e perdas dentárias, dificultando ainda mais a mecanicoterapia. Entretanto, uma das vantagens do tratamento ortodôntico em adultos é o controle da placa bacteriana, pois estes tendem a ser mais colaboradores no controle da higiene oral. Concluíram então que, para o 
sucesso do tratamento ortodôntico em adultos com perdas dentais e com doença periodontal, três itens são importantes: o paciente deve estar realmente motivado para enfrentar o tratamento; o acompanhamento por parte do periodontista durante todo o tratamento para a realização da manutenção da saúde periodontal; e o controle das forças ortodônticas por parte do ortodontista.

Em duas revisões sistemáticas, Bollen (2008), procurou avaliar se a má oclusão é prejudicial para o periodonto e se a correção da maloclusão pelo tratamento ortodôntico beneficia a saúde periodontal. A primeira revisão encontrou uma correlação entre a presença da maloclusão e a doença periodontal; quanto maior a maloclusão, mais severa a doença periodontal. A segunda identificou uma ausência de evidências confiáveis dos efeitos do tratamento ortodôntico na saúde periodontal

Pias \& Ambrósio (2008) propuseram um estudo de revisão para discutir a respeito da viabilidade e eficácia da intrusão ortodôntica como forma de reduzir os defeitos infraósseos provocados pela doença periodontal. O método utilizado foi uma revisão de literatura, em que os artigos usados foram as bases de dados MEDLINE, LILACS e BBO. As conclusões mostraram que se consegue um restabelecimento da estética e função, que esta correção consegue também um melhor acesso para a higienização e que reduz a carga não axial. Os movimentos ortodônticos de intrusão podem ser realizados em casos de migração dentária patológica e extrusão, desde que a inflamação periodontal tenha sido tratada, necessitando assim de uma ação multidisciplinar. A técnica do arco segmentado é a recomendada em virtude da sua habilidade em desenvolver forças leves ( 5 a $15 \mathrm{~g}$ ) e contínuas, que, quanto maior o defeito ósseo, menores devem ser as forças aplicadas e maiores os intervalos entre as ativações ortodônticas. A possibilidade de haver regeneração de tecido de suporte, a partir da intrusão, é controversa entre os autores, de maneira que a natureza histológica do processo não está confirmada. A associação de enxertos ósseos previamente à movimentação apresenta resultado favoráveis.

Elaborando uma revisão de literatura sobre o tratamento ortodôntico em pacientes com o periodonto de inserção reduzido, Carraro \& Jimenez-Pellegrin (2009) avaliaram que a doença periodontal é a causa da perda dos tecidos de sustentação, resultando em migrações patológicas dentárias, comprometimento da estética e da função mastigatória, principalmente em adultos, daí o aumento desses pacientes nos consultórios. Deve-se, para esses pacientes, fazer uma relação de fatores de risco, como: estresse, doenças sistêmicas, fumo, osteoporose e predisposição genética, e estes devem ser controlados antes do início do tratamento. Os objetivos e as limitações devem ser explicados ao paciente desde o início, pois em adolescentes a finalização pode chegar a um bom termo, porém em pacientes com periodonto reduzido, nem sempre se consegue alcançar a expectativa do paciente. Quanto à aparatologia, indicam o aparelho fixo $\mathrm{e}$, nos molares, é preferível tubo à banda, pois essas retêm mais placa, provocando inflamação nos tecidos periodontais, que podem ser temporárias e reversíveis, caso os limites biológicos sejam respeitados. O uso de forças leves e mais próximas ao centro de resistência são fatores importantes no controle da movimentação. Para o defeito horizontal, o melhor tratamento é o movimento puro de intrusão e, nos defeitos verticais, o mais indicado é a extrusão, pois o osso alveolar tende a acompanhar o movimento dentário no sentido oclusal; entretanto, se tiver envolvimento de furca, o movimento poderá exacerbar o problema periodontal. A idade não é um fator limitante, contudo, o prognóstico está relacionado ao grau do comprometimento periodontal. O tempo de contenção deve ser determinado individualmente, considerando a maloclusão inicial, o biótipo facial, a quantidade de periodonto de inserção presente e o tipo de movimento realizado.

Grantidis et al. (2010) realizaram uma revisão sistemática sobre a inter-relação ortodontia/periodontia no tratamento integrado, tendo em vista o continuo aumento de pacientes adultos procurando o tratamento ortodôntico, o que leva o ortodontista a enfrentar pacientes com problemas periodontais. Salienta que as considerações estéticas, como margens gengivais irregulares e problemas funcionais originários da doença periodontal inflamatória, devem ser consideradas no planejamento do tratamento ortodôntico. A literatura consultada assegura que, em casos de periodontite severa, a ortodontia pode aumentar as possibilidades de conservar e restaurar uma dentição deteriorada.

Nishi et al. (2011) avaliaram periodontalmente a adaptabilidade após a utilização de dois modelos de contenção fixa. A contenção reta e a contenção modificada foram comparadas entre si, 
na relação acúmulo de placa e na ocorrência de inflamação gengival. Também foram confrontadas a adaptabilidade do paciente e o conforto. Participaram 19 voluntários com bons alinhamentos e sem DP e, após 3 meses de contenção, foi feito o questionamento sobre adaptação, conforto e facilidade de higienização e qual desenho favoreceu o acúmulo de alimentos. O resultado é que não houve diferença significativa para índice de placa e índice de sangramento no período de 3 e 6 meses entre o reto e o modificado. A adaptação foi melhor para o reto, e a melhor higienização foi escolha a da contenção modificada. E esta também foi bem melhor para o uso do fio dental.

Maia et al. (2011) verificaram, também através de uma revisão de literatura, as alterações periodontais após a instalação de aparelho ortodôntico. Encontraram que a aparatologia ortodôntica pode apresentar um potencial para causar, indiretamente, alterações periodontias, devido ao acúmulo de biofilme em função da dificuldade de manutenção da higiene bucal adequada na presença de bandas e bráquetes. Existe também uma dúvida constante entre os clínicos se o tratamento ortodôntico pode promover uma recessão gengival. A conclusão dessa revisão foi de que a colocação de aparelhos ortodônticos, em pacientes com periodonto saudável, leva a um acúmulo de biofilme e inflamação gengival, influenciando a composição da microbiota subgengival indiretamente, em um curto período de tempo, após o início da ortodontia, porém são condições reversíveis em pacientes com boa higiene bucal. Já uma situação clínica mais avançada requer intervenções cirúrgicas e um programa de controle de manutenção adequado. $\mathrm{Na}$ presença de retrações gengivais, se o dente apresentar um tecido gengival espesso e a posição dentária estiver proeminente, não há necessidade de terapia adicional, entretanto, se a quantidade de gengiva insuficiente estiver associada a um dente que será vestibularizado, a necessidade de um enxerto gengival, antes da ortodontia, deve ser avaliada.

Grisi et al. (2011) fizeram uma revisão de literatura sobre questionamentos constantes em relação ao papel da ortodontia no aparecimento de lesões periodontais, e os estudos mostram que pacientes com periodonto sadio e inflamação controlada podem ser tratados ortodonticamente, já que, em condições de saúde periodontal, a ortodontia não resulta em significativa perda de inserção. A correção ortodôntica, por outro lado, pode favorecer o tratamento de defeitos infraósseos, pois estimula a aposição óssea, podendo diminuir a dimensão do defeito ósseo. A técnica regenerativa, se necessária, para tratamento de defeitos infraósseos, deve ser realizada anteriormente à ortodontia, fornecendo uma precondição mais favorável para o tratamento ortodôntico, já que esse não ocasiona nenhum efeito negativo ao novo aparato. Concluem que a terapia ortodôntica por si só não leva à formação de problemas periodontais, podendo ser benéfica, e para que a interação ortodontia e periodontia tragam benefícios, é importante o diagnóstico antes da terapia ortodôntica, um planejamento associado e uma comunicação entre os profissionais durante todo o tratamento ortodôntico.

Cirelli et al. (2013) comentam que, apesar de a doença periodontal ser tratável, as sequelas geradas devido à perda de tecidos periodontais prejudicam as funções do sistema estomatognático e afetam a estética, sendo importante, nesses casos, uma terapia multidisciplinar, na qual a associação com a ortodontia pode contribuir para melhorar as condições estética e funcionais. Assim, nos pacientes comprometidos periodontalmente, um planejamento conjunto do ortodontista com o periodontista deve ser feito para que se obtenha uma terapia apropriada e segura. Os autores lembram que estudos clássicos confirmam que a movimentação ortodôntica pode ser realizada, independente da idade do paciente, desde que o periodonto esteja saudável. Recomendam, assim, que especialmente nos pacientes de periodonto reduzido a doença periodontal deva ser eliminada previamente ao início do tratamento ortodôntico, e a saúde alcançada seja mantida durante todo o tratamento.

\section{DISCUSSÃO}

Observa-se um aumento contínuo de pacientes adultos na procura do tratamento ortodôntico, e esse fato ocorre pela crescente busca da população em geral pela preservação da dentição natural, bem como pelo aparecimento de problemas funcionais e estéticos (Pithon \& Bernardes, 2005; Carraro \& Jimenez-Pellegrin, 2009; Grantidis et al., 2010). Esses fatos fazem com que o ortodontista atual enfrente pacientes com diferentes graus de doença periodontal e suas sequelas, como um periodonto reduzido em suas dimensões. 
Com a preocupação de esclarecer e orientar os ortodontistas, quando enfrentam clinicamente esses pacientes, inúmeros estudiosos têm buscado verificar a inter-relação do tratamento ortodôntico com o periodontal, procurando determinar se o tratamento ortodôntico traz benefícios para os pacientes adultos periodontalmente comprometidos (Maia et al., 2011).

Assim, Ericsson et al. (1977) concluíram que, na presença de biofilme bacteriano e inflamação gengival, a movimentação ortodôntica aumenta a taxa de destruição do periodonto de inserção. Também de acordo estão Bassani et al. (2001), ao afirmarem que a movimentação em dentes com inflamação acarreta um risco aumentado de perda de inserção periodontal. $\mathrm{O}$ tipo de movimentação ortodôntica também pode acarretar danos ao periodonto, fato observado por Finkbeiner et al. (1997), ao estudarem os efeitos das bandas elásticas ortodônticas, que induziram ao aparecimento de recessão gengival, periodontite e mobilidade.

Bassani et al. (2001) relatam que as bandas ortodônticas são, indiscutivelmente, um fator dificultador no controle da placa, podendo propiciar o estabelecimento de uma microbiota subgengival diferenciada. Maia et al. (2011) vêm confirmar essas observações, ao afirmarem que a aparatologia ortodôntica pode apresentar um potencial para agravar, alterações periodontais, devido ao acúmulo de biofilme em função da dificuldade de manutenção da higiene bucal adequada na presença de bandas e bráquetes. Por essa razão, existe uma preocupação quanto ao tipo de aparelho indicado, e assim Carraro \& Jimenez-Pellegrin (2009), quanto à aparatologia, indicam o aparelho fixo e, nos molares, ser preferível tubo à banda, pois as bandas retêm mais placa, provocando inflamação nos tecidos periodontais, que podem ser temporárias e reversíveis, caso os limites biológicos sejam respeitados.

Nishi et al. (2011) avaliaram periodontalmente a adaptabilidade após a utilização de dois modelos de contenção fixa. A contenção reta e a contenção modificada foram comparadas entre si, na relação acúmulo de placa e na ocorrência de inflamação gengival. O resultado é que não houve diferença significativa para índice de placa e índice de sangramento no período de 3 e 6 meses entre a reto e a modificada. A adaptação do paciente foi melhor para a reta, mas a melhor higienização, incluindo o uso do fio dental, foi para a da contenção modificada.

Essas preocupações se justificam em virtude de que a movimentação ortodôntica realizada com a presença de placa e doença periodontal pode aumentar a taxa de destruição do periodonto de inserção (Ericsson et al., 1977; Costa et al., 2002; Cirelli \& Cirelli, 2003; Grisi et al., 2011).

Por esse motivo é que a maioria dos autores concordam que o tratamento ortodôntico deva ser realizado em condições de saúde periodontal, especialmente nos pacientes adultos com o periodonto comprometido pela doença periodontal. Melsen, já em 1986, conclui que o tratamento ortodôntico não resulta em diminuição do nível do osso marginal, em macacos periodontalmente saudáveis, providos de inflamação gengival controlada. Acrescenta que, na realização do tratamento ortodôntico, o controle da placa bacteriana, fator primário para prevenção da doença periodontal, é relevante para se obter sucesso terapêutico. Choze et al. (2002) afirmam que a literatura pesquisada foi consensual ao afirmar a importância do tratamento ortodôntico, como uma conduta importante auxiliar para dentes com suporte reduzido pela evolução da doença periodontal, enfatizando que os movimentos só deverão ser realizados em um periodonto livre de inflamação e/ou infecção. Cirelli \& Cirelli (2003) salientam que a prática da ortodontia causa alguns riscos ao paciente. Analisando esses riscos, concluem que o paciente periodontal apenas deve iniciar a ortodontia após a fase de tratamento da doença, e se inserido em um programa de terapia de suporte, pois nessas condições os riscos de complicações periodontais são praticamente nulos, mediante os benefícios que o tratamento integrado periodontia-ortodontia traz ao paciente. D'Ornellas et al. (2003) discorrerem sobre a conduta ortodôntica perante o paciente adulto acometido de doença periodontal. Como protocolo de tratamento, para eles o importante é o controle periodontal antes, durante e também após a colocação do aparelho, e o início da ortodontia deverá ser 6 meses após o término da periodontia, concordando com Cirelli \& Cirelli (2003). Zachrisson (2005) também sugere que o tempo de espera entre o tratamento periodontal e a colocação do aparelho ortodôntico seja de 2 a 6 meses, dependendo da motivação do paciente quanto à higienização bucal e, também, para que ocorra a reparação óssea. Grisi et al. (2011) 
concluem que os pacientes tratados periodontalmente podem fazer uso da ortodontia, pois ela favorece o tratamento dos defeitos infraósseos, porque estimula a aposição óssea, podendo assim diminuir a dimensão de defeitos ósseos. Contudo, o paciente deve ser tratado anteriormente à ortodontia, e é de fundamental importância para o sucesso que haja um bom diagnóstico prévio e uma comunicação entre os profissionais durante todo o tratamento ortodôntico. Cirelli et al. (2013) lembram que estudos clássicos confirmam que a movimentação ortodôntica pode ser realizada, independente da idade do paciente, desde que o periodonto esteja saudável. Recomendam que especialmente nos pacientes de periodonto reduzido, a doença periodontal deva ser eliminada previamente ao início do tratamento ortodôntico, e a saúde alcançada seja mantida durante todo o tratamento.

Essa manutenção da saúde periodontal durante o tratamento ortodôntico é considerada como fator essencial para o sucesso do tratamento (Ong et al., 1998; Costa et al., 2002; Cirelli \& Cirelli, 2003; D'Ornellas et al., 2003; Zachrisson, 2005; Pithon \& Bernardes, 2005). Para que isso se efetive, é necessário que haja uma real integração entre peridontistas e ortodontistas, e que uma comunicação entre esses profissionais seja constante, como sugerem Mathews \& Kokich (2001), e com o que concordam Pithon \& Bernardes (2005), Grisi et al. (2011) e Cirelli et al. (2013). Assim é importante que, com as informações do periodontista, o ortodontista realize um planejamento adequado do tipo de tratamento ortodôntico proposto e da construção do aparelho ortodôntico (Zachrisson, 1996). Choze et al. (2002) enfatizaram que os movimentos ortodônticos só deverão ser realizados através de forças leves e controladas para dentes com suporte reduzido pela evolução da doença periodontal. D'Ornellas et al. (2003) salientam que existem limites inerentes ao tratamento desses pacientes, como a escolha de uma ancoragem adequada e que o período de reativação deve ser de 3 a 4 semanas, podendo ser mudado de acordo com o caso do paciente. Pithon \& Bernardes (2005) concluíram que, para o sucesso do tratamento ortodôntico em adultos com perdas dentais e com doença periodontal, um dos itens importantes é o controle das forças ortodônticas por parte do ortodontista. Pias \& Ambrósio (2008), discutindo a respeito da viabilidade e eficácia da intrusão ortodôntica, como forma de reduzir os defeitos infraósseos provocados pela doença periodontal, recomendam a técnica do arco segmentado, em virtude da sua habilidade em desenvolver forças leves ( 5 a $15 \mathrm{~g}$ ) e contínuas, e que, quanto maior o defeito ósseo, menores devem ser as forças aplicadas e maiores os intervalos entre as ativações ortodônticas. Carraro \& Jimenez-Pellegrin (2009) também recomendam o uso de forças leves e mais próximas ao centro de resistência, fatores importantes no controle da movimentação. Essas observações, embora não tenhamos encontrado estudos mais específicos sobre a força que deva ser utilizada na movimentação ortodôntica de pacientes adultos, com periodonto reduzido pela doença periodontal, a literatura consultada nos leva a sugerir que os melhores resultados são obtidos nas mecânicas que utilizam forças leves e com controle das linhas de ação dessas forças.

No entanto, parecem não existir dúvidas quanto aos benefícios do tratamento ortodôntico nos pacientes com o periodonto reduzido (Nelson \& Artun, 1997; Cirelli \& Cirelli, 2003; Grantidis et al., 2010; Maia et al., 2011; Grisi et al., 2011; Cirelli et al., 2013) e que esses benefícios podem se manter ao longo do tempo (Re et al., 2000). As vantagens da ortodontia para esses pacientes seriam melhoras na função, higienização, redução de cargas não axiais, ganho de inserção, redução de defeito ósseo, restituição da oclusão incisal, melhor anatomia periodontal, aumento do selamento labial e melhora da estética (Bassani et al., 2001). Para que esses benefícios sejam alcançados, de acordo com Zachrisson (1996) e Pithon \& Bernardes (2005), três itens importantes devem ser observados: a instrução da higiene oral e motivação do paciente para enfrentar o tratamento; o planejamento e construção do aparelho ortodôntico para um controle das forças aplicadas pelo ortodontista; acompanhamento por parte do periodontista durante todo o tratamento ortodôntico. Cirelli et al. (2013) sintetizam esses itens, ao recomendarem que, especialmente nos pacientes de periodonto reduzido, a doença periodontal ativa deve ser controlada previamente ao início do tratamento ortodôntico, e a saúde alcançada seja mantida durante todo o tratamento ortodôntico, mesmo que o paciente apresente sequelas da doença periodontal, tais como perda óssea, recessões gengivais e perda de tecido queratinizado. 


\section{5- CONCLUSÕES}

Com base na literatura revisada, ao nosso alcance, em relação ao tratamento ortodôntico em pacientes com o periodonto reduzido, podemos chegar às seguintes conclusões;

1. A movimentação ortodôntica realizada com a presença de placa e doença periodontal pode aumentar a taxa de destruição do periodonto de inserção.

2. Nos pacientes de periodonto reduzido, a doença periodontal ativa deve ser eliminada previamente ao início do tratamento ortodôntico, e a saúde periodontal alcançada seja mantida durante todo o tratamento.

3. Os melhores resultados são obtidos nas mecânicas que utilizam forças leves e com controle das linhas de ação dessas forças.

4. O tratamento ortodôntico nos pacientes com periodonto reduzido pode gerar vários benefícios, tais como: reequilíbrio da oclusão, diminuição de defeitos infraósseos, verticalização e alinhamento de dentes, facilitando a higienização, restabelecimento da estética do sorriso e consequentemente da autoestima do paciente.

5. Para que os benefícios se efetivem, é necessário que haja uma real integração entre peridontistas e ortodontistas, e que uma comunicação entre esses profissionais seja constante durante todo o tratamento ortodôntico.

\section{6 - REFERÊNCIAS}

BASSANI, D. G., SILVA, C. M., \& CACHAPUZ, M. F. (2001). Inter-relação periodontia e ortodontia. In R. V. Oppermann, \& C. K. Rosing (Eds.), Periodontia: ciência e clínica (pp. 337-345). São Paulo: Artes Médicas.

BOLLEN, A. M. (2008). Effects of maloclusions and ortodontics on periodontal health: evidence from a sustematic review. Journal of Dental Education, 72(8), 912-918.

CARRARO, F. L. C., \& JIMENEZ-PELLEGRIN, C. (2009). Tratamento ortodôntico em pacientes com periodonto de inserção reduzido. $R G O$, 57(4), 455-458.

CHOZE, S., GUSMÃO, E. S., SANTOS, R. L., SILVEIRA, R. C. J. (2002). Intrusão ortodôntica no tratamento de dentes com inserção periodontal reduzida: estudo revisional. Jornal Brasileiro de Ortodontia \& Ortopedia Facial, 7(39), 258-262.

CIRELLI, J. A., NOGUEIRA, A. V. B., MOLON, R. S., BARROS, L. A. B., \& CIRELLI, C. C. (2013). Estética periodontal e periimplantar Estética no paciente tratado com sequelas de doença periodontal avançada. In R. V. Oppermann, \& C. K. Rosing (Eds.), Periodontia para todos (cap. 7, pp. 284-287). São Paulo: Napoleão Editora.

CIRELli, J. A., \& CIRELLI, C. C. (2003). Ortodontia no tratamento periodontal: quando indicar e quais são os riscos? In R. F. M. Lotufo, \& N. T. Lascala Junior (Eds.), Periodontia e implantodontia: desmistificando a ciência (pp. 316-335). São Paulo: Artes Médicas.

COSTA, L. F. M., SANTOS, D. M., \& LOURENÇO Junior, E. T. (2002). Avaliação radiográfica do nível de reabsorção radicular e perda óssea alveolar pré e pós-tratamento ortodôntico. Jornal Brasileiro de Ortodontia \& Ortopedia Facial, 7(41), 407-413.

D’ORNELLAS, M. C., HAHN, L., \& MARCHIORO, E. M. (2003). Abordagem ortodôntica frente ao paciente periodontal adulto. Stomatos, 9(16), 7-13.

ERICSSON, I., THILANDER, B., LINDHE J., OKAMOTO, H. (1977). The effect of orthodontic tilting movements on the periodontal tissues of infected and noninfected dentitions in the dog. Journal of Clinical Periodontology, 4, 78-293.

FINKBEINER, R. L., NELSON, L. S., \& KILLEBREW, J. (1997). Accidental orthodontic elastic band induced periodontitis: orthodontic and laser treatment. The Journal of the American Dental Association, 128, 1565-1569.

GRANTIDIS, N., CHRISTOU, P., \& TOPOUZELIS, N. (2010). The orthodonticperiodontic interrelationship in integrated treatment challenges: a systematic review. Journal of Oral Rehabilitation, 37(5), 377-390.

GRISI, M. M., MAIA, L. P., SOUZA, S. L. S., \& TABA, M. (2011). Ortodontia e periodontia - Parte II: papel auxiliar da terapia ortodôntica no tratamento periodontal. Brazilian Journal Periodontology, 21(3), 46-52.

GUSMÃO, E. S., JOVINO-SILVEIRA, R. C., \& SANTOS, R. L. (2005). Inter-relação da 
periodontia com a ortodontia. In J. S. Paiva, \& R. V. Almeida (Eds.), Periodontia: a atuação clínica baseada em vidências científica (cap. 27, pp. 423-425). São Paulo: Artes Médicas.

MAIA, L. P., NOVAIS Júnior, A. B., SOUZA, S. L. S., PALIOTP, D. B., TABA Junior, M., GRISI, M. F. M. (2011). Ortodontia e periodontia-Parte 1: alterações periodontais após a instalação de aparelho ortodôntico. Brazilian Journal Periodontology, 21(3), 40-45.

MATHEWS, D. M., \& KOKICH, V. G. (2001). Tratamento de pacientes ortodônticos com problemas periodontais. Seminários em Ortodontia, 3(1), 21-38.

MELSEN, B. (1986). Tissue reaction following application of extrusive and intrusive forces to teeth in adult monkeys. American Journal of Orthodontics, 89(6), 469-475.

NELSON, P. A., \& ARTUN, J. (1997). Alveolar bone loss of maxillary anterior teeth in adult orthodontic patients. American Journal of Orthodontics and Dentofacial Orthopedics, 111, 328-334.

NISHI, R., BOMBARDELLI, C., NASSAR, P. O., BOMBONATTI, R., BUSATO, P. M. R., BUSATO, M. C. A. (2011). Avaliação periodontal e de adaptabilidade após utilização de dois modelos de contenção ortodôntica fixa. Revista Clínica de Ortodontia Dental Press, 10(5), 82-89.

ONG, M. A., WANG, L., SMITH, F. N. (1998). Interrelation between periodontics and adult orthodontics. Journal of Clinical Periodontology, 25(4), 271-277.

PIAS, A. C., \& AMBRÓSIO, A. P. (2008). Movimento ortodôntico intrusivo para reduzir defeitos infraósseos em pacientes periodontais. $R G O, 56(2), 181$.

PITHON, M. M., \& BERNARDES, L. A. A. (2005). Tratamento ortodôntico em pacientes adultos com perdas dentárias e doença periodontal. Jornal Brasileiro de Ortodontia \& Ortopedia Facial, 10(56), 142-147.

RE, S., CORRENTE, G., ABUNDO, R., \& CARDAROPOLI, D. (2000). Ortodontic treatment in periodontally compromised patients: : 12-year report. The International Journal of Periodontics \& Restorative Dentistry, 20(1), 31-39.

ZACHRISSON, B. U. (1996). Clinical implication of recent orthodontic-periodontic research findings. Seminars in Orthodontics, 2, 4-12.

ZACHRISSON, B. U. (2005). Ortodontia e periodontia. In J. Lindhe, T. Karring, \& N. P. Lang (Eds.), Tratado de periodontia clínica e implantologia oral (4. ed., cap 31, pp. 721-758). Rio de Janeiro: Guanabara/Koogan.

ZACHRISSON, B. U., \& BJORN, T. (2005). Bonding in orthodontics. In L W Graber (Ed.), Orthodontics: current principles and techniques (4th ed., pp. 621-659). Saint Louis: Mosby. 